\title{
Laryngopharyngeal reflux in chronic obstructive pulmonary disease - a multi- centre study
}

\author{
Julia Sanchez ${ }^{1}$, Desiree M. Schumann¹, Meropi Karakioulaki ${ }^{1}$, Eleni Papakonstantinou, Frank Rassouli², \\ Matthias Frasnelli ${ }^{3}$, Martin Brutsche ${ }^{2}$, Michael Tamm ${ }^{1}$ and Daiana Stolz ${ }^{1^{*}}$
}

\begin{abstract}
Reflux of gastric content has been associated with recurrent exacerbations of chronic obstructive pulmonary disease (COPD). We aimed to assess the prevalence of laryngopharyngeal reflux (LPR) in COPD and if LPR is a contributing factor to clinically relevant outcomes in COPD. We evaluated a total of 193 COPD patients (GOLD I-IV) with a 24-h laryngo-pharyngeal pH-monitor. LPR was observed in 65.8\% of COPD patients and it was not significantly associated with clinically relevant outcomes of COPD. Treatment with PPI significantly decreased the upright RYAN score $(p=0.047)$ without improving lung function. Furthermore, the presence or severity of LPR cannot be diagnosed based solely on symptoms and questionnaires.
\end{abstract}

Keywords: Laryngopharyngeal reflux, Chronic obstructive pulmonary disease, Proton pump inhibitor therapy, RYAN score, Gastroesophageal reflux

\section{Background}

Chronic obstructive pulmonary disease (COPD) is a chronic respiratory disease and one of the leading causes of mortality worldwide [1]. The clinical severity of COPD is determined by comorbidities, one of which is the gastroesophageal reflux disease (GERD) [2-5]. GERD is a common cause of chronic cough [6] and a potential risk factor for exacerbations of COPD [7-10]. Frequent exacerbators have a high prevalence of GERD, however approximately $58 \%$ of these patients lack typical GERD symptoms $[11,12]$.

Laryngopharyngeal reflux (LPR) represents an extraesophageal manifestation of GERD. The reflux of gastric contents is fundamental in both LPR and GERD, but the mechanism and the symptoms of the disorders are distinct [13-15]. LPR occurs when gastric contents pass

\footnotetext{
* Correspondence: Daiana.Stolz@usb.ch

${ }^{1}$ Clinic of Respiratory Medicine and Pulmonary Cell Research, University Hospital Basel, Petersgraben 4, CH-4031 Basel, Switzerland

Full list of author information is available at the end of the article
}

the upper esophageal sphincter and usually occurs during daytime in the upright position, while GERD occurs when gastric contents pass the lower esophageal sphincter and takes place more often in the supine position at night-time or during sleep [16]. LPR may be a contributing factor in patients with symptomatic COPD however, there are only a few studies analyzing the impact of LPR in patients with COPD $[13,17,18]$. In a large longitudinal study of COPD patients, selfreported GERD or use of PPIs was associated with a 20$60 \%$ increased risk of moderate-severe exacerbations and hospitalized exacerbations during 3 years of follow up [19]. Yet, this study was based on a subjective, selfreported history of a physician's diagnosis of GERD and studies based on objective evaluations by laryngealpharyngeal $\mathrm{pH}$ monitoring in a large COPD cohort are still missing. Here, we investigated the prevalence of LPR and explored its association with clinically relevant outcomes of COPD. 


\section{Methods}

We included 193 patients with mild to severe COPD (GOLD I-IV). All patients completed the GERD questionnaire (GerdQ) and the Reflux symptom index (RSI), in order to assess reflux symptoms and the Leicester cough questionnaire, in order to assess life quality disturbance due to cough. Additionally, patients were evaluated for the prevalence of LPR and its association with lung function. The presence of LPR was assessed by trained and certified study nurses. Participants were fitted with a pharyngeal probe (Restech $\mathrm{pH}$ probe, Respiratory Technology Corp.) for $24 \mathrm{~h}$. The $\mathrm{pH}$ was measured twice per second and was transmitted wirelessly to a data recorder. The thresholds for detecting LPR were for the upright position: RYAN score $>9.41$ and for the supine position: RYAN score $>6.81$ [20].

A subgroup of 107 patients belonged to a prospective, multicenter study [PREVENT, ISRCTN 45572998 [21, 22]] and was longitudinally assessed for 2 years (median follow-up period of 12 months) for an association between LPR and clinically relevant outcomes of COPD. In this pre-defined cohort, 41 patients had 67 mild acute exacerbations of COPD (AECOPD), defined as an acute worsening of respiratory symptoms leading to a change in medication and 37 patients had 62 severe AECOPD, requiring hospitalization. Among these 107 patients, 34 patients agreed to undergo a second evaluation of LPR after 1 month on PPI treatment (Supplementary Figure 1).

\section{Results}

The descriptive characteristics of the patients are presented in Table 1A. Risk categories were defined for 106 of the 107 patients from the pre-defined cohort as follows: 8 in GOLD A, 63 in GOLD B, 4 in GOLD C and 31 in GOLD D.

The median (IQR) upright RYAN score was 37.01 (2.12-186.89) and the median (IQR) supine RYAN score was $2.17(2.17-5.50)$. Totally, $65.8 \%(n=127)$ of the patients had LPR, as detected by either a pathologic upright RYAN score $(n=85,44.0 \%)$, or a pathologic supine RYAN score $(n=5,2.6 \%)$, or both upright and supine pathologic RYAN scores $(n=37,19.2 \%)$ (Fig. 1a).

There was no association between upright or supine RYAN score and lung function measurements $\left(\mathrm{FEV}_{1} \%\right.$ predicted, $p=0.076$ and $p=0.488$, respectively; RV \% predicted, $p=0.282$ and $p=0.800$, respectively; TLC \% predicted, $p=$ 0.054 and $p=0.559$, respectively; Fig. $2 \mathrm{a}$ and $\mathrm{b}$ ).

In the pre-defined cohort with 2-years follow-up, linear regression analysis revealed that there was no association between the upright RYAN score and COPD severity, as revealed by the 6-min walking test, the BODE index, and lung function (Table 1B). Furthermore, there was no association between the upright RYAN and COPD outcome as revealed by the number of exacerbations during the study (Table 1B). Similar results were also obtained for the supine RYAN score (Fig. 2b). However, there was a significant positive association between the upright RYAN score and age (Beta = $0.239, p=0.013)$, and a negative association with GerdQ (Beta $=-0.257, p=0.008)$ (Table 1B).

There were no significant differences between patients with positive LPR and patients with negative LPR in GerdQ score $(1.9 \pm 3.3$ vs $2.1 \pm 3.3, p=0.177)$, Leicester cough score $(93.9 \pm 40.0$ vs $103.3 \pm 32.8, p=0.227)$ and RSI $(9.9 \pm 9.0$ vs $9.4 \pm 9.6, p=0.905)$.

Using Cox regression and adjusting the model for age and PPI therapy, we found no effect of upright RYAN score neither on time to exacerbation $(\operatorname{Exp}(\mathrm{B}) 1.325, p=$ $0.369)$ nor on time to severe exacerbation $(\operatorname{Exp}(B) 1.195$, $p=0.722)$.

Within the pre-defined cohort with 2-year follow-up, 34 COPD patients were reevaluated for LPR, after 1 month on PPI treatment. There was a significant decrease in the upright RYAN score after treatment $(p=0.047)$ but not in the supine RYAN score $(p=0.285)$ (Fig. 2b). Comparing lung function before and after 1 month on PPI treatment, we found no significant difference in lung function parameters, or in any of the questionnaire scores.

\section{Discussion}

To our knowledge, this is the largest study assessing LPR prevalence in a well-characterized COPD cohort. We assessed LPR by monitoring laryngopharyngeal $\mathrm{pH}$ [19] and we could demonstrate that the prevalence of LPR is high in COPD patients $(65.8 \%)$. This is in agreement with the study of Hamdan et al. [13], where the RSI questionnaire was utilized to determine the presence of LPR in 27 COPD patients and $67 \%$ of them scored positive for LPR. In our study, there was no association between LPR and clinically relevant COPD outcomes within a 2-year follow-up period, contrary to the findings of Jung et al. [17], who found an association between the RSI score, the reflux finding score and severe exacerbations in 118 COPD patients. These discrepancies could be attributable to the fact that Jung et al. [17] refrained from objectively analyzing LPR prevalence and their diagnosis was based solely on symptoms. Additionally, as stated by Jung et al. [17], the respiratory symptoms of COPD, such as excess throat mucus, cough, throat clearing, and dysphonia, coincide with the measurements of the RSI questionnaire. Therefore, during an exacerbation of COPD, these symptoms would increase automatically, resulting in an increase in the RSI score, independently of LPR. Jung et al. [17] found no association between RSI, RFS, and COPD severity or any other lung function parameter, except between RFS and residual volume / total lung capacity (\%).We found no association between the questionnaire results (GerdQ-Questionnaire, RSI to 
Table 1 [A]: Descriptive characteristics of the patients included in the study; [B]: Linear regression model for the effect of various parameters in the upright RYAN score in the pre-defined cohort with 2-year follow-up

\begin{tabular}{|c|c|c|c|c|}
\hline \multicolumn{5}{|l|}{$[\mathrm{A}]$} \\
\hline Descriptive characteristics & \multicolumn{2}{|c|}{$\begin{array}{l}\text { All patients } \\
n=193\end{array}$} & \multicolumn{2}{|c|}{$\begin{array}{l}\text { Pre-defined cohort } \\
\text { with 2-year follow-up } \\
n=107\end{array}$} \\
\hline Age (years), mean (SD) & \multicolumn{2}{|c|}{$66.2(8.8)$} & \multicolumn{2}{|l|}{$67.5(8.4)$} \\
\hline BMI $\left(\mathbf{k g} / \mathbf{m}^{2}\right)$, mean (SD) & \multicolumn{2}{|c|}{$27.1(6.7)$} & \multicolumn{2}{|l|}{$27.8(6.6)$} \\
\hline Medical history of GERD, n (\%) & \multicolumn{2}{|l|}{$33(17)$} & \multicolumn{2}{|l|}{$16(15)$} \\
\hline Treated with PPI, n (\%) & \multicolumn{2}{|l|}{$69(37)$} & \multicolumn{2}{|l|}{$33(30.8)$} \\
\hline Gender, male (\%) & \multicolumn{2}{|c|}{$119(62)$} & \multicolumn{2}{|l|}{$75(70)$} \\
\hline \multicolumn{5}{|l|}{ Smoking status, $\mathrm{n}(\%)$} \\
\hline Current & \multicolumn{2}{|l|}{$62(34)$} & \multicolumn{2}{|l|}{$38(36)$} \\
\hline Past & \multicolumn{2}{|c|}{$121(66)$} & \multicolumn{2}{|l|}{$69(64)$} \\
\hline \multicolumn{5}{|l|}{ GOLD Stage, n (\%) } \\
\hline I & \multicolumn{2}{|l|}{$25(14)$} & \multicolumn{2}{|l|}{$6(6)$} \\
\hline$\|$ & \multicolumn{2}{|l|}{$82(45)$} & \multicolumn{2}{|l|}{$58(58)$} \\
\hline III & \multicolumn{2}{|l|}{$55(30)$} & \multicolumn{2}{|l|}{$32(32)$} \\
\hline IV & \multicolumn{2}{|l|}{$21(11)$} & $4(4)$ & \\
\hline COPD Medication & & & & \\
\hline LABA & $55(28)$ & & $19(18)$ & \\
\hline$L A B A+I C S$ & $151(78$ & & $102(96)$ & \\
\hline LAMA & $129(67)$ & & $81(76)$ & \\
\hline SABA & $26(13)$ & & $2(2)$ & \\
\hline SAMA & $39(20)$ & & $35(33)$ & \\
\hline Lung Function (post-BD), mean & & & & \\
\hline $\mathrm{FEV}_{1} \%$ predicted & $56.9(21$ & & $57.4(16.4)$ & \\
\hline RV \% predicted & $144.3(4$ & & $136.6(46.7)$ & \\
\hline TLC \%predicted & $110.5(2$ & & $107.9(20.5)$ & \\
\hline DLCO\% predicted & $61.0(22$ & & $57.7(18.5)$ & \\
\hline $\mathrm{FEV}_{1} / \mathrm{FVC}$ & $46.9(14$ & & $46.9(13.1)$ & \\
\hline Questionnaire scores, mean (SD & & & & \\
\hline GerdQ & $2.1(3.3)$ & & $2.1(3.2)$ & \\
\hline Leicester cough & $96.5(38$ & & $104.6(27.1)$ & \\
\hline RSI & 10.0 & & $10.1(8.4)$ & \\
\hline$[B]$ & & & & \\
\hline Parameter & $\begin{array}{l}\text { Pre-def } \\
(n=107\end{array}$ & rt with 2-year fo & & \\
\hline & Beta & 95\% Cl: Lower & 95\% Cl: Upper & $p$-value \\
\hline Age & 0.239 & 0.006 & 0.050 & 0.013 \\
\hline 6MWT & -0.073 & -0.002 & 0.001 & 0.474 \\
\hline BODE Index & 0.004 & -0.099 & 0.103 & 0.969 \\
\hline Lung Function & & & & \\
\hline $\mathrm{FEV}_{1} \%$ predicted & -0.010 & -0.013 & 0.012 & 0.923 \\
\hline TLC \% predicted & -0.182 & -0.019 & 0.001 & 0.091 \\
\hline RV \% predicted & -0.142 & -0.007 & 0.001 & 0.177 \\
\hline
\end{tabular}


Table 1 [A]: Descriptive characteristics of the patients included in the study; [B]: Linear regression model for the effect of various parameters in the upright RYAN score in the pre-defined cohort with 2-year follow-up (Continued)

\begin{tabular}{|c|c|c|c|c|}
\hline Number of exacerbations during the study & 0.015 & -0.175 & 0.205 & 0.877 \\
\hline Number of severe exacerbations during the study & -0.011 & -0.305 & 0.272 & 0.911 \\
\hline \multicolumn{5}{|l|}{ Questionnaires } \\
\hline GerdQ & -0.257 & -0.139 & -0.022 & 0.008 \\
\hline Leicester cough & 0.012 & -0.007 & 0.008 & 0.899 \\
\hline RSI & -1.013 & -0.034 & 0.011 & 0.314 \\
\hline
\end{tabular}

95\% Cl 95\% confidence interval, BMI body mass index, GERD gastroesophageal reflux disease, PPI proton pump inhibitors, GOLD Global Initiative for Chronic Obstructive Lung Disease, LABA long acting beta 2 agonist, $L A B A+I C S$ long-acting beta 2 agonist plus glucocorticosteroids, LAMA long-acting muscarinic antagonist, $S A B A$ short-acting beta 2 agonist, $S A M A$ short-acting muscarinic antagonist, post- $B D$ post-bronchodilator, $F E V$, forced expiratory volume in $1 \mathrm{~s}, R V$ residual volume, $T L C$ total lung capacity, $D L C O$ diffusing capacity of the lung for carbon monoxide, GerdQ gastroesophageal reflux disease questionnaire, $R S I$ Reflux symptom index, BODE Index Body mass, airflow obstruction, dyspnea and exercise capacity index, 6MWT 6-min walking test

assess reflux symptoms and the Leicester cough questionnaire to assess lifetime quality disturbance due to cough) and RYAN score results which confirms findings in other studies $[23,24]$.

Currently, the main treatment for LPR is PPI. We found that in patients receiving PPI for 30 days, there was a significant decrease in the upright RYAN score but no improvement in lung function nor in symptoms, as assessed by the various questionnaires used. Further long-term investigations are required to clarify this finding though these results have been seen with GERD treatment [25] and LPR treatment for 2-months in COPD patients [18]. The findings are also in-line with the recent ERS guidelines on chronic cough, suggesting that PPI therapy is not beneficial for patients with reflux without dyspeptic symptoms [26].

Among the limitations of our study is the short follow-up period after PPI therapy. However, it was possible to determine a significant decrease in the upright RYAN score after 1 month on PPI. Within the strengths of our study is its multicentric design and the large wellcharacterised COPD cohort included.

\section{Conclusions}

LPR is not significantly associated with clinically relevant outcomes of COPD. Treatment with PPI significantly decreased the upright RYAN score without improving lung function. Our results further indicate that the

[A]

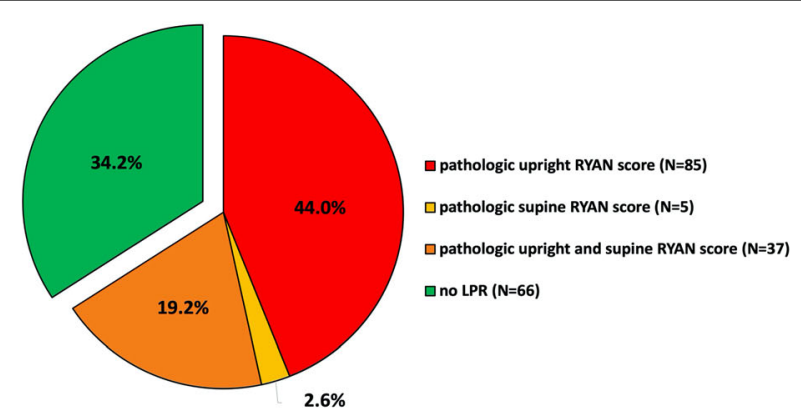

[B]
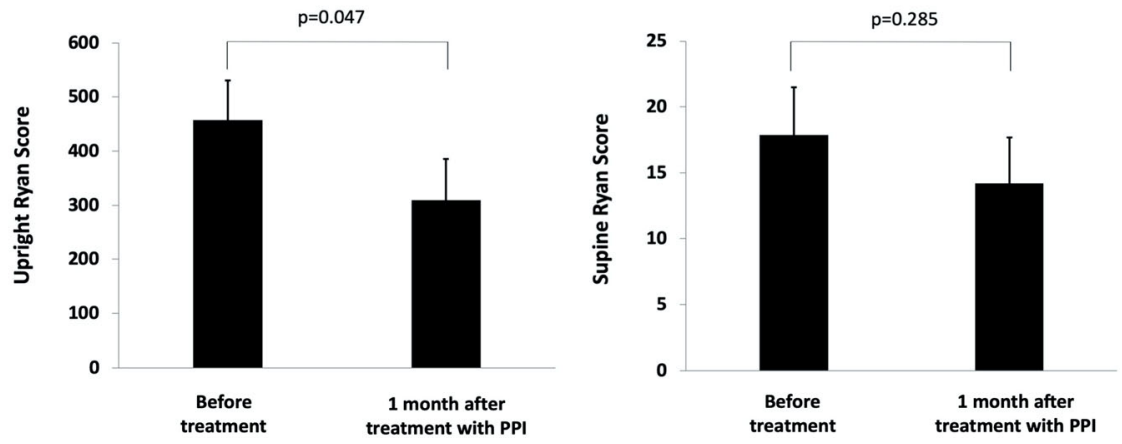

Fig. 1 [a] Prevalence of LPR in COPD patients. [b] RYAN score in upright and supine position before treatment and after 1-month of protonpump inhibitor (PPI) treatment in 34 COPD patients. Bars represent the mean \pm standard error of mean 


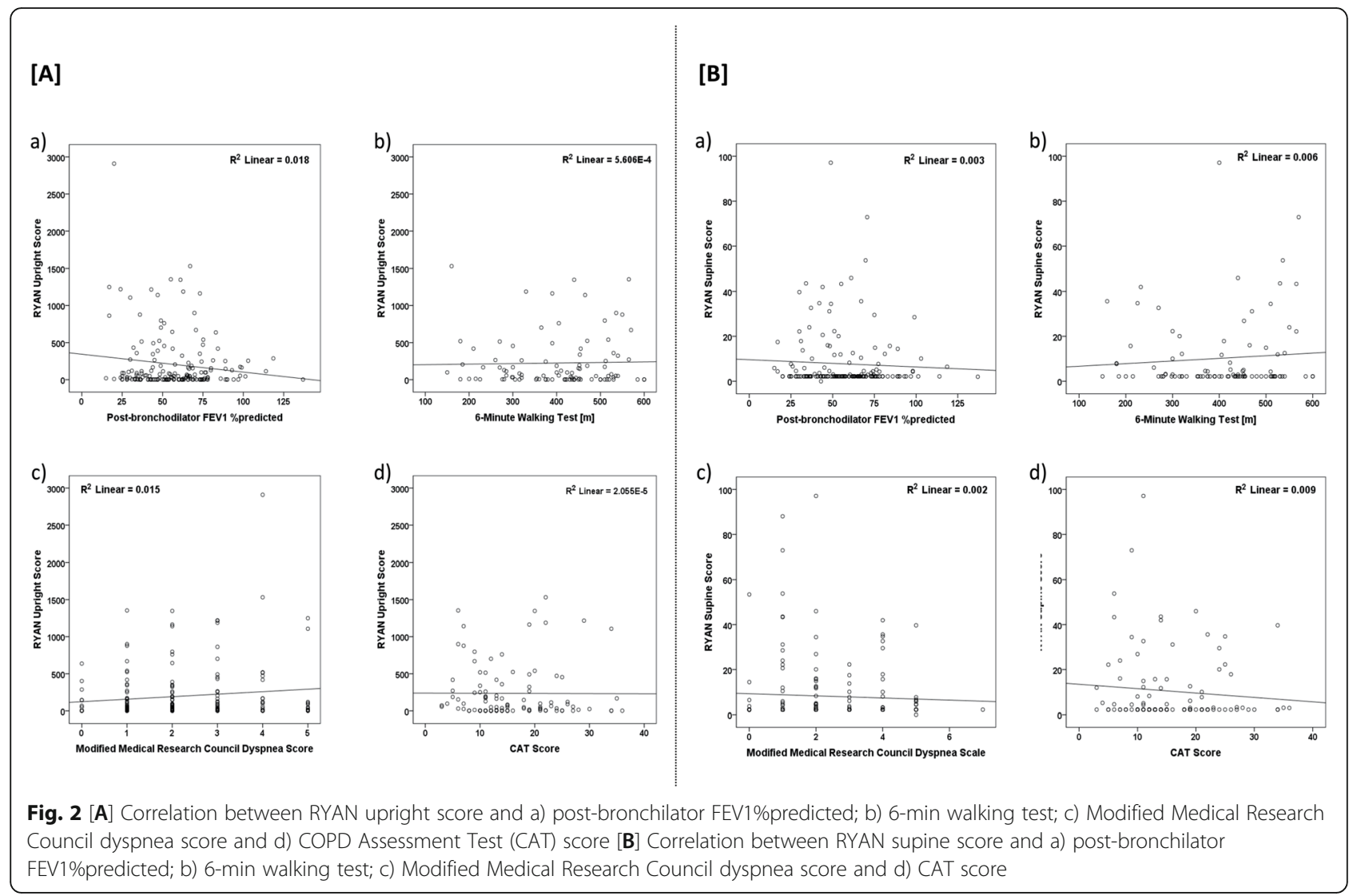

presence or severity of LPR cannot be diagnosed based solely on symptoms and questionnaires.

\section{Supplementary information}

Supplementary information accompanies this paper at https://doi.org/10. 1186/s12931-020-01473-2.

\section{Additional file 1.}

\section{Abbreviations}

AECOPD: Acute exacerbations of COPD; BODE index: Body mass, airflow obstruction, dyspnea and exercise capacity index; Cl: Confidence interval; CAT: COPD Assessment Test; COPD: Chronic obstructive pulmonary disease; DLCO: Diffusing capacity of the lung for carbon monoxide; FEV ${ }_{1}$ : Forced expiratory volume in $1 \mathrm{~s}$; FVC: Forced vital capacity; GerdQ: Gastroesophageal reflux disease questionnaire; GERD: Gastroesophageal reflux disease;

GOLD: Global initiative for chronic obstructive lung disease;

LPR: Laryngopharyngeal reflux; PPI: Proton pump Inhibitors; RSI: Reflux symptom index; RV: Residual volume; TLC/RV: Residual volume to total lung capacity ratio; TLC: Total lung capacity

\section{Acknowledgments}

Not applicable.

\section{Guarantor statement}

D. Stolz takes full responsibility for the content of the manuscript, including the data and the analysis thereof.

\section{Authors' contributions}

Data collection, accuracy of data, statistical analysis, writing of the manuscript, contribution to the discussion of results, finalization of the manuscript and approval of the submitted article: SJ, SDM, KM, PE, RF, FM,
BM, TM, SD; conception of the research project, contribution in clinical work, integrity and accuracy of data, preparation and approval of the submitted article: SD. The author(s) read and approved the final manuscript.

\section{Funding}

The PREVENT study was primarily funded by a Swiss National Foundation grant to Prof. D. Stolz (PP00-P3_128412/1) and by the Clinic of Respiratory Medicine and Pulmonary Cell Research of the University Hospital Basel.

\section{Availability of data and materials}

The datasets used and analysed during the current study are available from the corresponding author on reasonable request.

\section{Ethics approval and consent to participate}

All patients consent to participate in the study. The study was approved by the ethics committee of the University Hospital, Basel (EKBB306/10).

\section{Consent for publication}

All patients signed informed consents for publication of their data in the study.

\section{Competing interests}

All authors declare that they have no competing interests.

\section{Author details}

${ }^{1}$ Clinic of Respiratory Medicine and Pulmonary Cell Research, University Hospital Basel, Petersgraben 4, CH-4031 Basel, Switzerland. ${ }^{2}$ Department of Pneumology, Kantonsspital St. Gallen, Rorschacherstrasse 95, St. Gallen CH-9001, Switzerland. ${ }^{3}$ Department of Pneumology, Kantonsspital Graubünden, Loestrasse 170, Chur CH-7000, Chur, Switzerland. 
Received: 13 May 2020 Accepted: 27 July 2020

Published online: 21 August 2020

\section{References}

1. Global Initiative for Chronic Obstructive Lung Disease. Global strategy for the diagnosis, management and prevention of chronic obstructive pulmonary disease http://goldcopd.org/global-strategy-diagnosismanagement-prevention-copd-20162017 [cited 2017 February, 14].

2. Barnes PJ, Celli BR. Systemic manifestations and comorbidities of COPD. Eur Respir J. 2009;33(5):1165-85.

3. Celli BR, MacNee W. ATS/ERS task force. Standards for the diagnosis and treatment of patients with COPD: a summary of the ATS/ERS position paper. Eur Respir J. 2004;23(6):932-46.

4. Clini EM, Boschetto P, Lainscak M, Janssens W. Comorbidities in chronic obstructive pulmonary disease from assessment to treatment. Biomed Res Int. 2014;2014:414928.

5. Nussbaumer-Ochsner Y, Rabe KF. Systemic manifestations of COPD. Chest. 2011;139(1):165-73.

6. Pratter MR. Overview of common causes of chronic cough: ACCP evidencebased clinical practice guidelines. Chest. 2006;129(1 Suppl):59S-62S.

7. Baumeler L, Papakonstantinou E, Milenkovic B, Lacoma A, Louis R, Aerts JG, et al. Therapy with proton-pump inhibitors for gastroesophageal reflux disease does not reduce the risk for severe exacerbations in COPD. Respirology. 2016;21(5):883-90

8. Sakae TM, Pizzichini MM, Teixeira PJ, Silva RM, Trevisol DJ, EP. Exacerbations of COPD and symptoms of gastroesophageal reflux: a systematic review and meta-analysis. J Bras Pneumol. 2013;39(3):259-71.

9. Rascon-Aguilar IE, Pamer M, Wludyka P, Cury J, Coultas D, Lambiase LR, et al. Role of gastroesophageal reflux symptoms in exacerbations in COPD. Chest. 2006;130(4):1096-101.

10. Lin YH, Tsai CL, Chien LN, Chiou HY, Jeng C. Newly diagnosed gastroesophageal reflux disease increased the risk of acute exacerbation of chronic obstructive pulmonary disease during the first year following diagnosis - a nationwide population-based cohort study. Int I Clin Pract. 2015:69(3):350-7.

11. Casanova C., Baudet JS., del VAlle Velasco M., Martin JM., Aguirre-Jaime A., de Torres JP., et al. Increased gastro-oesophageal reflux disease in patients with severe COPD. Eur Respir J 2004;23(6):841-845.

12. Iliaz S, lliaz R, Onur ST, Arici S, Akyuz U, Karaca C, et al. Does gastroesophageal reflux increase chronic obstructive pulmonary disease exacerbations? Respir Med. 2006;115:20-5.

13. Hamdan AL, Ziade G, Turfe Z, Beydoun N, Sarieddine D, Kanj N. Laryngopharyngeal symptoms in patients with chronic obstructive pulmonary disease. Eur Arch Otorhinolaryngol. 2016;273:953-8.

14. Oelschlager BK, Chang L, Pope CE 2nd., Pellegrini CA. Typical GERD Symptoms and esophageal $\mathrm{pH}$ monitoring are not enough to diagnose pharyngeal reflux. J Surg Res. 2005;128(1):55-60.

15. Hamdan AL, Jaffal H, Btaiche R, Turfe ZA, Bawab I, Kanj N, et al. Laryngopharyngeal symptoms in patients with asthma: a cross-sectional controlled study. Clin Respir J. 2016;10:40-7.

16. Ylitalo R, Thibeault SL. Relationship between time of exposure of laryngopharyngeal reflux and gene expression in laryngeal fibroblasts. Ann Otol Rhinol Laryngol. 2006;115(10):775-83.

17. Jung YH, Lee DY, Kim DW, Park SS, Heo EY, Chung HS, et al. Clinical significance of laryngopharyngeal reflux in patients with chronic obstructive pulmonary disease. Int J Chron Obstruct Pulmon Dis. 2015;10:1343-51.

18. Eryuksel E, Dogan M, Olgun S, Kocak I, Celikel T. Incidence and treatment results of laryngopharyngeal reflux in chronic obstructive pulmonary disease. Eur Arch Otorhinolaryngol. 2009;266(8):1267-71.

19. Benson VS, Mullerova H, Vestbo J, Wedzicha JA, Patel A, Hurst JR, et al. Associations between gastro-oesophageal reflux, its management and exacerbations of chronic obstructive pulmonary disease. Respir Med. 2015: 109(9):1147-54.

20. Ayazi S, Lipham JC, Hagen JA, Tang AL, Zehetner J, Leers JM, et al. A new technique for measurement of pharyngeal pH: normal values and discriminating pH threshold. J Gastrointest Surg. 2009;13(8):1422-9.

21. Stolz D, Papakonstantinou E, Grize L, Schilter D, Strobel W, Louis R, et al. Time-course of upper respiratory tract viral infection and COPD exacerbation. Eur Respir J. 2019;54(4):1900407.

22. Stolz D, Hirsch HH, Schilter D, Louis R, Rakic J, Boeck L, et al. Intensified therapy with inhaled corticosteroids and long-acting $\beta$ (2)-agonists at the onset of upper respiratory tract infection to Prevent chronic obstructive pulmonary disease exacerbations. A multicenter, randomized, double-blind, placebo-controlled trial. Am J Respir Crit Care Med. 2018;197(9):1136-46.

23. Kilic M, Ozturk F, Kirmemis O, Atmaca S, Guner SN, Caltepe G, et al. Impact of laryngopharyngeal and gastroesophageal reflux on asthma control in children. Int J Pediatr Otorhinolaryngol. 2013;77(3):341-5.

24. Wang G, Qu C, Wang L, Liu H, Han H, Xu B, et al. Utility of 24-hour pharyngeal pH monitoring and clinical feature in laryngopharyngeal reflux disease. Acta Otolaryngol. 2019;139(3):299-303.

25. Broers C, Tack J, Pauwels A. Review article: gastro-oesophageal reflux disease in asthma and chronic obstructive pulmonary disease. Aliment Pharmacol Ther. 2018;47(2):176-91.

26. Morice AH, Millqvist E, Bieksiene K, Birring SS, Dicpinigaitis P, Domingo Ribas $C$, et al. ERS guidelines on the diagnosis and treatment of chronic cough in adults and children. Eur Respir J. 2020;55(1):1901136.

\section{Publisher's Note}

Springer Nature remains neutral with regard to jurisdictional claims in published maps and institutional affiliations.

\section{Ready to submit your research? Choose BMC and benefit from:}

- fast, convenient online submission

- thorough peer review by experienced researchers in your field

- rapid publication on acceptance

- support for research data, including large and complex data types

- gold Open Access which fosters wider collaboration and increased citations

- maximum visibility for your research: over $100 \mathrm{M}$ website views per year

At BMC, research is always in progress.

Learn more biomedcentral.com/submissions 